\title{
PEer LeARning AND LEAdERSHIP IN ENGINEERING DESIGN AND Professional Practice
}

\author{
Amy Hsiao, Grant McSorley, and David Taylor \\ School of Sustainable Design Engineering, University of Prince Edward Island \\ ahsiao@upei.ca
}

\begin{abstract}
This work presents an assessment of the development of leadership skills in fourth-year engineering students, who are project leads of teams that comprise of third-year engineering students in a yearlong Engineering Design and Professional Practice course. It is proposed that the success of peer learning is directly related to the growth and change in the project leads, the progress of the followers, and the strength of the leader-follower engagement. As such, this work will compare classroom observations with Leader-MemberExchange (LMX) theory and the concepts of servant leadership and authentic leadership in the context of an engineering workplace. This work will also discuss both the value of the inputs and the measure of the outcomes in this peer mentorship scenario, i.e. starting with the importance of the individual in peer mentorship, through reflection, goal-setting, and self-awareness, to the importance and practice of designated project lead management meetings, to the significance of knowledge transfer in the learning process. The challenges of peer learning at the undergraduate level will also be discussed. In presenting this work, the authors would like to promote knowledge sharing of how peer mentorship and the development of leadership skills have been implemented and assessed effectively in Engineering at other universities.
\end{abstract}

Keywords: peer learning and mentorship, project-based teamwork, authentic and servant leadership, leaderfollower exchange.

\section{INTRODUCTION}

This work presents an assessment of peer learning and the development of leadership skills in the context of a unique year-long Senior Engineering Design project and Professional Practice course at the School of Sustainable Design Engineering (SSDE) at the University of Prince Edward Island (UPEI). The unique focus of the Bachelor in Science in Sustainable Design Engineering program is experiential learning in the form of community and client focused engineering design projects. In every semester, students participate in project-based design courses in which they work in teams under faculty supervision to solve real-world engineering problems. The focus of this paper is the year-long senior engineering design client- based project and professional practice course completed by third and fourth year students.

This program differentiates itself from other student design and capstone projects by integrating third and fourth year students into the same design teams, with one or more fourth year student assigned with lead project management and technical roles within the team. As a result of current class sizes, the teams for the 2016-17 year consisted of one fourth year student teamed with two or three third year students. The primary objective of this structure is to promote the development of leadership and mentoring skills within the fourth year engineering students. It is also believed that peer learning and mentorship from more experienced students will promote greater professional and personal growth among the team members than traditional programs where team leads are selected from the same cohort.

Within the structure of this course, students work together as "junior engineers" in an engineering consultancy start-up scenario, where the company has three chief officers (the instructors) and has grown from having two client projects in its first year to seven projects this year. The students are scheduled to attend class in three-hour-periods over four mornings of the week, with most of that time designated for Engineering Design (team project work) and at least one class period per week focused on Professional Practice. As such, students are presented a series of modules (lectures or activities) to support their development as designers and professional engineers. While certain modules are combined, the majority of classroom interaction is targeted to specific third or fourth year objectives in separate modules.

\subsection{Professional Development}

In their roles as team members, the third year students were guided through modules in the first semester focused on understanding concepts from Organizational Behaviour, i.e. team development and team roles, communication, organizational structure, client relationships, managing stress and conflict, and leadership styles. A self-reflection or self-application summary was submitted for each topic. In the second semester, the third year students focused on topics that focused on professional development, i.e. intellectual property, ethics, equity and equity, and empathy, health and 
wellness, and life-long learning.

In their roles as team leads, the fourth year students were supported through project management and leadership modules, as well as through bi-weekly team lead meetings, where instructors met with the team leads to discuss team progress and challenges they were facing on team dynamics, project planning and logistics, and leadership. Finally, in the second semester, fourth year students were required to complete a self-assessment and personal development assignment, where they identified and worked to improve an area of weakness.

\subsection{Professional Practice}

In addition to individual and team presentations and demonstrations to clients, industry guests, staff, and faculty, students were guided in professional development through the engineering consultancy structure. As the chief officers, the course instructors conducted performance reviews with each student one month into the project and at the half-way point of the project (at the beginning of the second semester). The performance reviews focused on qualitative feedback from peers and instructors, using "strengths" and "areas for improvement" as points of discussion with each student. In addition, all students completed peer feedback following the completion of project deliverables. These activities and assessments form the basis for the analysis of leadership and peer learning effectiveness presented in this paper.

\subsection{Developing Leadership in Engineering Students}

There is a growing recognition that engineers have a professional responsibility to take on leadership roles within the workplace as well as within society as whole [1]. However, barriers persist due to the technical nature of the engineering profession and tendency for engineering institutions to relegate leadership training and practice to extracurricular activities [1]. As described in section 1.2 and 1.3, the SSDE program attempts to correct this by integrating leadership modules directly into the design and professional practice courses. As part of the senior design program, two distinct but overlapping concepts of leadership were emphasized: servant leadership and authentic leadership.

Servant leadership focuses on the leader as a servant, whose first motivation is to serve the organization and their followers. This implies characteristics such as enabling and empowering followers, humility, authenticity, acceptance, providing direction, and stewardship [2]. Authentic leadership, while similar, emphasizes leadership as an expression of one's true self, and is characterized by being authentic in interaction with others, while demonstrating open-mindedness and a willingness to change [2].
With their emphasis on the relationship between leader and follower, the promotion of personal growth and empowerment, and the open exchange of ideas, these concepts fit well within the context of the LeaderMember-Exchange (LMX) theory, which posits that "positive, beneficial actions directed at subordinates by their supervisors contribute to the development of highquality exchange relationships that create obligations for the subordinates to reciprocate in equally positive ways" [3].

As such, LMX, authentic leadership, and servant leadership all emphasize the importance of mentorship, collaboration and the promotion of professional and personal growth of the team members through positive interactions. These concepts will form the basis for analysing the results of the leadership oriented activities complete by the project teams.

\subsection{Defining Peer Learning}

The literature presents at least two strong definitions of peer learning, one of which is given by the example of the "flipped classroom", and the other in which "peer learning" is also known as "cooperative learning" [4] [5]. In the first definition, peer learning occurs when a group of students prepare and teach, or transfer knowledge, to another group of students. There are normally core concepts that must be understood and explained from one individual or group to another individual or group of students. In the definition of "cooperative learning", there is a direct academic and indirect social interdependence in which group members must fully participate, and group processing must occur, for the group to become a successful team [6]. This paper focuses on peer learning as cooperative learning.

\section{RESULTS AND ANALYSIS}

\subsection{Follower Reflections}

There were a total of five topics for reflection by the third year students in the first semester. In the first assignment, the class of twenty students were asked to reflect upon their workplace style-personality and initial thoughts on the company's orientation activities.

\footnotetext{
"During Design class we took a personality test, I am a 'Driver,' which I think suits me very well. I enjoyed how we went over the different types of learning styles because I am a driver and never actually took too much thought in the other learning styles. This exercise has made me much more aware of the Expressive, Analytical and Amiable personality types. I needed this since my team consists of two "Amiable," one "Expressive," and me the "Driver." Now I have a better understanding of each members
} 
personalities; this was my first time meeting [other members] from my team, and now I know how they will react and handle situations. Since I am a driver I need to work on letting others take the leadership role, and taking into how other people like to discuss things a lot."

Students were also asked to reflect on the qualities of servant and authentic leadership by mid-project, which was the end of the first semester.

\begin{abstract}
"Servant leadership is a way of behaving that you can adopt over time, by focusing others needs before your own. I have had peers evaluate my leadership capacities, the results have proven that I often underestimate myself and aren't always aware of my full potential. Seeing the results on how my peers believe I am a successful servant leader and that I exhibit all seven of the characteristics of servant leadership makes me very proud of my work and efforts I put into being an engineer. I am very proud and encouraged by the results of what other people think of me, and it will help to continue working on these important leadership qualities. It makes me happy to know that I am successful as one of the few female students in the engineering studies."
\end{abstract}

In these cases, students chose to reflect upon traits and characteristics in themselves that empowered them as team members.

When reflecting upon their project leads at the beginning of the year, team members expected authentic and servant leadership, using words such as "he stepped up", "he made sure we all got along," "he controls his emotions", and "he tends to ask questions rather than give orders."

"I haven't been in a team that I didn't need to take the role of the leader. [He] has stepped up as the 4th year student to be the team leader, which I very happy with because one of his main concerns throughout the design project is making sure that we all get along."

"[He] is the team leader and sole 4th year student on our team. During the Social Styles lecture, [he] was shown to be Analytical. This meant that he could control his emotions far better than everyone else but tended to ask questions rather than give orders. This will be a huge asset to our team because our client is focused on receiving a functional prototype at the end of the year and having an analytical member on the team who is detail-oriented will make the prototype stand out and function well. The last two members of the team are [both] with Amiable personality styles. Both tend to show emotions openly and would rather ask questions rather than give orders. Since Amiables and Analyticals have these traits in common, we expect to gel instantly giving us a great start to our tight-scheduled project."

\subsection{Leader Reflections}

In the second week of class, fourth year students were introduced to the use of coaching techniques to promote leader-follower exchange, where the team lead asks open ended questions to encourage reflection on the part of the team member and to encourage open dialogue. This was further reinforced as a leadership tool through the biweekly team lead meetings with instructors.

During these sessions, the instructors applied a similar method of asking open ended questions, allowing the team leads themselves to develop potential solutions among themselves before the instructors provided additional input. Topics included accountability, communication, coordination of activities, and stress management. At the end of each meeting, students committed themselves to working to resolve a particular team issue and report back on their experience at the next meeting. In this way, team leads were able to share their experiences, both positive and negative.

A representative scenario involved how to develop a common understanding among team members of the accepted level of quality for documentation, and how to ensure that all team members performed to similar levels. The solution passed through three phases:

(i) Separate parts were sent to one team member, typically the team lead, who then compiled and edited each section, which is typically frustrating for the editor.

(ii) The team lead would comment on the drafts sent, and return them for correction by the individual author. This was found to be inefficient and ineffective.

(iii) The draft was reviewed as a team, with all members providing feedback and discussing whether certain language or information was appropriate.

While the quality of deliverables continued to be a point of discussion, this application of peer learning and collaboration was found by the teams to be more effective than the process of providing individual feedback. This was also reflected in the overall increase in deliverable quality.

During the second semester, team leads were required to complete a self-assessment and personal development assignment, identifying an existing weakness, developing an action plan, tracking the execution and reflecting on the process. While there was no requirement that the development activity pertain to leadership skills, the students were required to reflect on how the process impacted their team and their personal role in the project.

Four of seven students identified permanent skills to improve, such as communication and professionalism, but 
only one explicitly identified leadership as an area to be developed. Despite this, five of the seven students included reflections explicitly pertaining to the evolution of their leadership abilities. Three examples are provided below with extracts from reflections.

"What I learned from this experience primarily was how to have a direct conversation with the intention of addressing a problem and seeking a solution [which is] uncomfortable and awkward at first[...]. As I found myself having similar conversations throughout the semester, they became easier to approach. I did not expect to acquire [this ability] but I will always be able to draw off this experience if I encounter difficult team members or colleagues in the future." (Targeted Competency: Communication)

"I also noticed a large change in my group's ability to effectively communicate the design components and problems they may be having with them to receive relevant feedback. I believe that this came about as a result of my own personal development.[...] Due to this, I feel much more confident in my abilities as the lead of an engineering design team. I feel much more confident in reaching out for feedback and seeking criticisms. I feel that this is an important skill for team leads to instill in the other members, as this is the most effective way to find improvements which can be made to a design."

\section{(Targeted Competency: Seeking expert feedback)}

"[A]fter working with individuals whose level of perfectionism is slightly lower, I developed a better understanding for when perfectionism is appropriate, and when it is not. I implemented this during team work on final project deliverables, which reduced overall stress levels of each member of the team significantly, and due to time considerations, was found to be an appropriate action to make." (Targeted Competency: Programming)

In each case, the project leads reflected on how the process affected their interactions with other team members, as well as the impact on themselves and the team. It further reinforced the need for open mindedness and an ability to adapt in order to be a successful leader.

\subsection{Peer Evaluations}

Table 1 shows an example peer evaluation used by students to evaluate their team members after each project deliverable: (1) Update 1, (2) Update 2, (3) Mid-Project, (4) Test Report, (5) Demonstration Presentation and (6) Final Presentation. The progression of improvement can be seen as the project continues through the academic year for each criterion: contribution to team, quality of work, professionalism, availability, and communication. Along with the numerical feedback, students were required to include comments to support their evaluations, recognizing team member strengths and providing suggestions for improvements.

Table 1: Peer Evaluation

\begin{tabular}{|l|c|c|c|c|c|c|}
\cline { 2 - 7 } \multicolumn{1}{c|}{} & 1 & 2 & 3 & 4 & 5 & 6 \\
\hline Contribution & 2.3 & 3.8 & 4.5 & 4.5 & 4.2 & 4.5 \\
\hline Quality of Work & 2.6 & 4.0 & 4.2 & 4.2 & 4.2 & 4.5 \\
\hline Communication & 3.0 & 4.0 & 4.2 & 4.5 & 4.5 & 4.7 \\
\hline Professionalism & 3.3 & 3.7 & 4.2 & 4.2 & 4.2 & 4.5 \\
\hline Availability & 2.7 & 3.7 & 4.3 & 4.3 & 4.5 & 4.8 \\
\hline Average (/5) & 2.8 & 3.8 & 4.3 & 4.3 & 4.3 & 4.6 \\
\hline Final (/100) & 56 & 77 & 86 & 87 & 87 & 92 \\
\hline
\end{tabular}

Fig. 1 shows the average of marks in each peer evaluation criteria for all 24 students, indicating an improvement in overall teamwork as the project progresses.

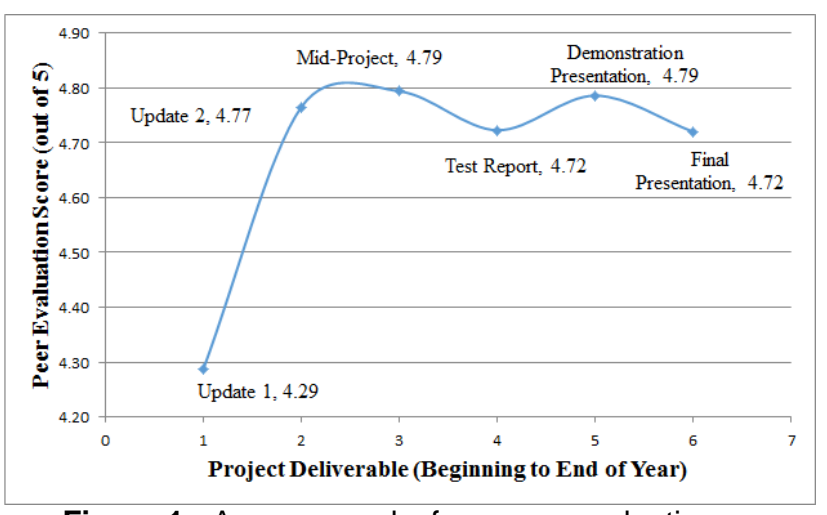

Figure 1: Average marks from peer evaluation as projects progress

Fig. 2 show that the average peer evaluation mark is slightly higher for fourth year project leads than for third year project team members. 


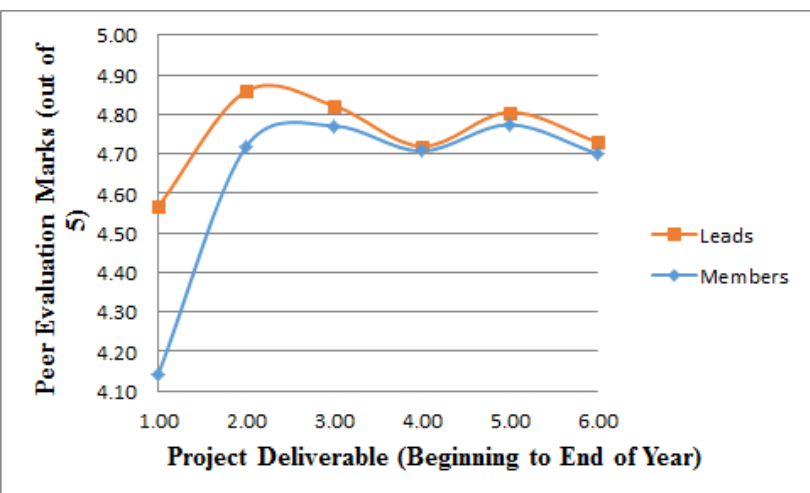

Figure 2: Comparison of peer evaluation marks for project leads and team members

\subsection{Assessment of Leadership Growth}

To examine the quality of the leader member exchange within the project teams, an analysis was completed of the written feedback provided to project leads by their third year teammates following each review. This was completed by analyzing the content of each sentence for one of three characteristics, as presented in Table 2.

Table 2: Peer Evaluation Feedback Characteristics

\begin{tabular}{|l|l|}
\hline Characteristic & Description \\
\hline Leadership & $\begin{array}{l}\text { Recognition of positive leadership } \\
\text { characteristics, including support of } \\
\text { team growth, collaboration, teaching and } \\
\text { openness }\end{array}$ \\
\hline $\begin{array}{l}\text { Constructive } \\
\text { Criticism }\end{array}$ & Suggestion provided for improvement \\
\hline $\begin{array}{l}\text { Negative } \\
\text { Feedback }\end{array}$ & $\begin{array}{l}\text { Problem identified with no suggestion of } \\
\text { how to improve }\end{array}$ \\
\hline $\begin{array}{l}\text { Recognition of } \\
\text { Improvement }\end{array}$ & $\begin{array}{l}\text { Explicit recognition of improvement to } \\
\text { project contribution }\end{array}$ \\
\hline
\end{tabular}

As can be seen in Fig. 3, while the number of sentences relating directly to leadership qualities as well as both constructive criticism and negative feedback decrease throughout the project, recognition of improvement increases slightly. While the trend in leadership characteristics may at first indicate a reduction in leadership ability in the team leads, this is not reflected in the numerical feedback provided. Furthermore, the proportion of positive leadership feedback is consistently higher than of purely negative feedback, indicating that the overall impression remains positive.

The data also reflects the large variation in evaluation and type of feedback between teams. For example, Figs. 4 and 5 show the results for two project leads. As can be expected, in cases where the team lead is evaluated quite strongly, as for student one, there is only minimal feedback provided. For student 2, the opposite is true, where the perceived weakness in leadership skills is outweighed by constructive feedback.



Figure 3: Average occurrence of feedback characteristics

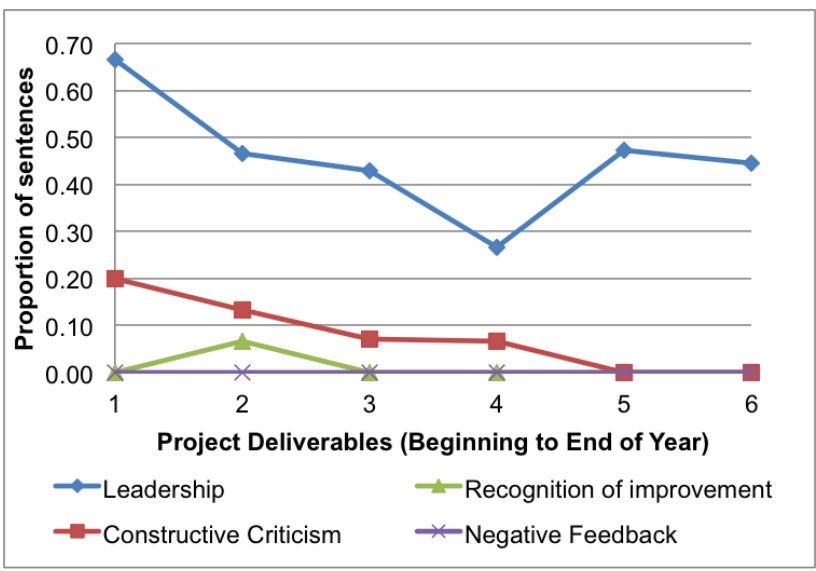

Figure 4: Feedback characteristics for perceived strong leader

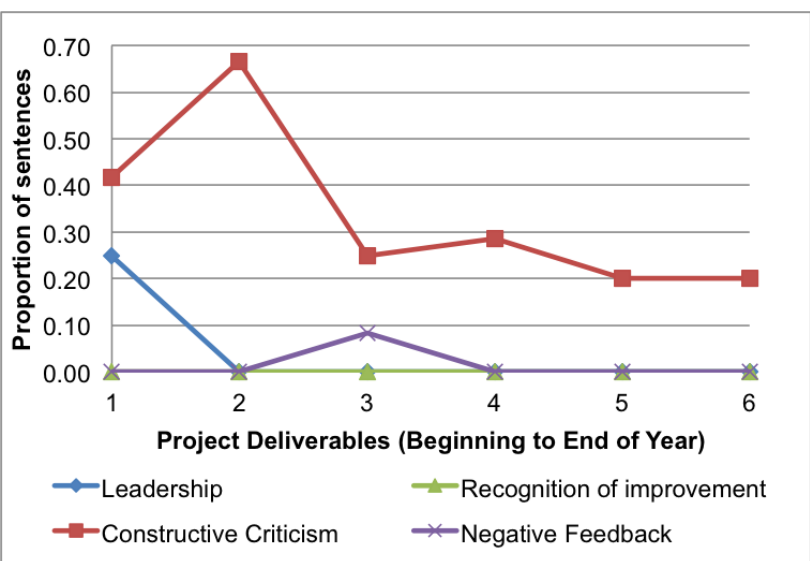

Figure 5: Feedback characteristics for perceived weak leader 
Furthermore, as the team dynamic evolves throughout the project, it is believed that the team members become more comfortable in providing true feedback to their team leads, seeing them as collaborators, rather than purely as supervisors. This can be seen in the relative increase in both constructive criticism and recognition of improvement in Fig. 3. This is further reflected in the content of the feedback. For example, in one case, the feedback evolved from pertaining only to leadership:

$$
\begin{aligned}
& \text { "A good team leader who is organized and } \\
& \text { supportive." }
\end{aligned}
$$

To feedback recognizing the team lead as a contributing team member:

\section{"[Team lead] was critical in the overall success of the design project, was able to effectively communicate with the client and various members of facilities $[\ldots]$ "..}

\section{DISCUSSION}

To be consistent with the objectives of peer learning and leadership in Engineering Design and Professional Practice, two of the learning outcomes, mapped to the Canadian Engineering Accreditation Board (CEAB)'s graduate attributes of Individual and Teamwork and Professionalism, as defined by the instructor in the course syllabus for the Year 4 course were:

- Act in a leadership role to facilitate the completion of assigned deliverables while mentoring teammates and demonstrating an ability to support effective team performance;

- Demonstrate professionalism, including honesty and integrity, and an understanding of the engineers role to support the broader community Similarly, the learning outcomes for the Year 3 course, correlated to the $\mathrm{CEAB}$ graduate attributes of Individual and Teamwork and Professionalism were:

- Work in an Engineering Practice setting;

- Communicate technical information in a professional and effective manner;

- Build positive connections between colleagues and the organization;

- Consider and evaluate the individual and teambuilding aspects of a professional engineer

A particular challenge is objectively evaluating the development of leadership abilities among the team members. While the reflections from team members set clear expectations for the team leads and projected clear "praise" for one's own leadership qualities, the peer evaluation as conducted does not provide a clear answer as to whether these expectations were met. Furthermore, the self-reported development of leadership skills from the team leads is perceived improvement, and it remains difficult to evaluate the actual progress made. These are questions to be addressed in future research.

Nonetheless, peer learning as a cooperative endeavor in which daily interaction and communication were critical to the success of the team's project, successful team development, and individual leadership growth appears to be evident in this study. Peer learning as defined as cooperative learning appears to have been achieved when teams were able to engage in "group processing", in which the actions and decisions of each team member were evaluated for the effectiveness of contribution towards the team and project goals, e.g. as reflected through peer evaluation results [6]. Group processing occurred through daily academic and social engagement, such that leadership, trust-building, and peer mentorship between project leads and team members were experienced and reflected upon, as evidenced by the feedback collected. Peer learning as defined as peer teaching, on the other hand, was not as successful or evident.

\section{CONCLUSION}

As peer learning and the development of leadership skills are intrinsically related to the CEAB Graduate Attributes, engineering educators are seeking ways to integrate both into engineering curriculum in an innovative manner. This work assessed whether peer learning is directly related to the growth and change in project leads, the individual development of team members, and the strength of the leader-follower engagement. This work discussed the importance of individual leadership development in peer learning, through reflection, goal-setting, self-awareness, and the importance and practice of management meetings. Peer learning and the development of leadership skills together has the potential to elevate the level of academic challenge for students, promote active and collaborative learning, revolutionize student-faculty interactions, and enrich the engineering educational experience.

\section{References}

[1] Cindy Rottmann, Robin Sacks, and Douglas Reeve, "Engineering leadership: Grounding leadership theory in engineers' professional identities," Leadership, vol. 11, no. 3, pp. 351-373, 2015.

[2] Dirk van Dierendonck, "Servant Leadership: A Review and Synthesis," Journal of Management, vol. 37, no. 4, pp. 1228-1261, 2011.

[3] Ziguang Chen, Wing Lam and Jian An Zhong, "Leadermember exchange and member performance: A new look at individual-level negative feedback-seeking behavior and team-level empowerment climate," Journal of Applied Psychology, vol. 92, no. 1, pp. 202-212, 2007.

[4] Crouch, C.H.; Mazur, E. "Peer instruction: Ten years of experience and results,".American Journal of Physics. 69: 
970-977, 2001.

[5] Johnson, D.W. "An Educational Psychology Success Story: Social Interdependence Theory and Cooperative Learning". Educational Researcher. 38 (5): 365-379, 2009.

[6] Ross, J.,\& Smythe, E. "Differentiating cooperative learning to meet the needs of gifted learners: A case for transformational leadership". Journal for the Education of the Gifted, 19, 63-82, 1995. 